\title{
THREE DIMENSIONAL DEFORMATION OF MINING AREA DETECTION BY INSAR AND PROBABILITY INTEGRAL MODEL
}

\author{
H. D. Fan*, X. X. Gao, D. Cheng, W. Y. Zhao, C. L. Zhao \\ Jiangsu Key Laboratory of Resources and Environmental Information Engineering, China University of Mining and Technology, \\ Xuzhou 221116, China - cumtfanhd@163.com
}

\author{
Commission VII, WG VII/6
}

KEY WORDS: D-InSAR, deformation monitoring, probability integral method, genetic algorithm, land subsidence

\begin{abstract}
:
A new solution algorithm that combined D-InSAR and probability integral method was proposed to generate the three dimensional deformation in mining area. The details are as follows: according to the geological and mining data, the control points set should be established, which contains correct phase unwrapping points in subsidence basin edge generated by D-InSAR and several GPS points; Using the modulus method to calculate the optimum parameters of probability integral prediction; Finally, generate the three dimensional deformation of mining work face by the parameters. Using this method, the land subsidence with big deformation gradients in mining area were correctly generated by example TerraSAR-X images. The results of the example show that this method can generate the correct mining subsidence basin with a few surface observations, and it is much better than the results of D-InSAR.
\end{abstract}

\section{INTRODUCTION}

China is rich in mineral resources, approximately 4,000,000 hectares land area were destroyed by mining, and still increasing at an annual rate of 200,000 hectares. In all kinds of mineral resources, coal accounted for about $70 \%$ of primary energy consumption in china, because of long time and large scale mining lead to most of the mining area are facing with serious ground subsidence(Fan H D et al,2015). With the accelerated pace of the mine construction, the surface subsidence disaster warning, subsidence compensation and governance, ecological environment restoration, recycling waste subsidence and other derivative problems appeared gradually, and the key to solve these problems is clear the law of mining subsidence, this must be based on enormous measured data of surface subsidence inversion and analysis (Fan H D et al,2011). Unfortunately, the traditional monitoring methods (leveling, GPS, total station measurements) have high precision, but there is a heavy workload, high cost, measuring point sparse and other shortcomings, difficult to obtain the three-dimensional deformation and historical subsidence information(Fan H D et al,2012). In addition, these methods require a large number of ground monitoring points, it's difficult to ensure that preserve and emplace a large surface monitoring points because exist problems such as occupation of the land, the worker-peasant relations and other issues.

D-InSAR (Differential Interferometric Synthetic Aperture Radar) (Gabriel A K et al,1989)is a kind of advanced earth observation technology, which has all-time, all-weather, wide coverage and high accuracy advantage, and gradually widely used in seismic deformation extraction(Zhang G H et al,2011), landslide disaster monitoring(Han Y F et al,2010), subsidence monitoring because of loss water(Francesca $\mathrm{C}$ et al,2012) and other fields. However, the technique is easily affected by the decorrelation of time and space, and its application conditions are quite harsh. In particular, the majority of mine in china are covered by vegetation, large topographic relief (Midwest), the mining subsidence because of resource exploitation has a very large deformation gradient, it's difficult to solve correctly using the existing D-InSAR technique, which greatly limits the application of D-InSAR technique in the mining surface monitoring ( $\mathrm{Ng} \mathrm{A} \mathrm{H}$ et al, 2011;Ng A H et al,2012; Fan H D et al,2012).

D-InSAR technology is difficult to obtain the large deformation of surface subsidence, to solve the above problem. This paper puts forward a solution based on the mining subsidence theory of probability integration method, under the fusion of D-InSAR monitoring results and a small amount of measured surface subsidence, extracted surface subsidence basin respectively under the condition of actual mining.

\section{SUBSIDENCE MONITORING CAPABILITY OF D- INSAR}

Use the D-InSAR technology to monitor surface subsidence in mining area, SAR image pairs in addition to keeping short time interval and small vertical baseline conditions, the wavelength and the spatial resolution also can't be ignored. Massonnet and other scholars had given that D-InSAR technique can detect the theory formula of the maximum deformation gradient, that is (Massonnet D et al,1998):

$$
D=\frac{\lambda}{2 \mu}
$$

where $\quad \mu=$ pixel side length

$$
\lambda=\text { wavelength }
$$

In the multi-look conditions, for ERS and Envisat satellite Cband SAR image, the wavelength is $56 \mathrm{~mm}$, the resolution is $20 \mathrm{~m}$, D is 0.0014; ALOS satellite's L-band SAR image, the wavelength is $230 \mathrm{~mm}$, the resolution is $10 \mathrm{~m}, \mathrm{D}$ is 0.0125 ; TerraSAR-X satellite's X-band SAR image, the wavelength is $32 \mathrm{~mm}$, resolution is $1 \mathrm{~m}, \mathrm{D}_{L}$ is 0.016 . Obviously, only from the maximum available unwrapping phase gradient, ERS satellite images detection capability for large deformation is much less than TerraSAR satellite images. However, TerraSAR satellite

\footnotetext{
* Corresponding author
} 
revisit cycle is short and the resolution is high, but the $\mathrm{X}$-band wavelength is shorter, it is strongly influenced by noise such as vegetation, and its cost is very high, during the test we found that the L-band ALOS satellite is the best satellite monitoring of mining subsidence at the current.

\section{THE RESEARCH METHODS}

In China, probability integration method (He G Q et al,1991) is a prediction theory of mining subsidence in mining subsidence movement and deformation. As shown in Figure1(Fan H D et $\mathrm{al}, 2014)$, take the ground coordinate system xOy and coal seam coordinate system $\mu \mathrm{O}_{1} \nu$, the mining unit $\mathrm{B}(\mu, v)$ in inclined coal seam. According to the principle of the probability integral method, the subsidence of any surface point $(x, y)$ caused by mining can be expressed as:

$$
\begin{aligned}
& W(x, y)=m q \cos \alpha \iint W_{e o i}(x, y) d x d y \\
& W_{e o i}(x, y)=\frac{l}{r^{2}} \exp \left(\frac{-\pi\left(x-x_{i}\right)^{2}}{r^{2}}\right) \exp \left(\frac{-\pi\left(y-y_{i}+H_{i} \operatorname{ctg} \theta\right)^{2}}{r^{2}}\right)
\end{aligned}
$$

where

$$
\mathrm{q}=\text { the subsidence coefficient }
$$

$\mathrm{r}=$ the main influence radius

$$
\mathrm{r}=\mathrm{H}_{0} / \tan \beta
$$

$\mathrm{H}_{0}=$ the average mining depth

$\theta=$ the mining influence angle

$\tan \beta=$ the tangent of the main influence angle

$x_{i}, y_{i}=$ the planar coordinate of mining unit $\mathrm{i}$

$x, y=$ the coordinate of any surface point

$\mathrm{m}=$ the thickness of the coal seam

The spatial coordinate system is shown in Figure 1.

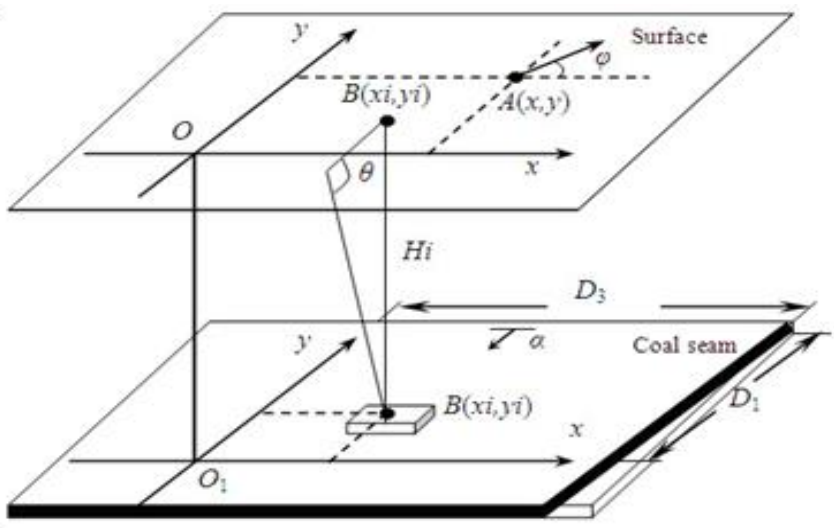

Figure 1. Spatial coordinate system of mining

The key to predict surface mining subsidence by probability integral method is to determine the subsidence coefficient $(q)$, the tangent of main influence angle $(\tan \beta)$, the mining influence angle $(\theta)$ and horizontal movement coefficient $b$ (this defaults to the common value of 0.3 ). These parameters are mainly inversed by a certain amount of surface movement monitoring data. Therefore, the traditional methods have some disadvantaged including heavy workload, high cost, insufficient density of field observation points, and it is necessary to study parameter inversion method based on new techniques and methods.

Therefore, in this paper, the subsidence of sinking basin edge points generated by D-InSAR and few GPS points (near the maximum subsidence and inflection points) were combined to calculate the parameters of probability integral method by formula (1), and then the inversion parameters were used to estimate three-dimensional surface subsidence caused by mining subsidence.

\section{TEST ANALYSIS}

The study area is located in Yulin city of Shanxi province, in northwest of China, which is one of the largest coal production bases. Thirteen scenes of TerraSAR-X images which were provided by the German Aerospace Centre (DLR) from April 2, 2013 to December 13, 2012 were selected to carry out the 2pass approach. Then the time series D-InSAR results were accumulated which were shown in Figure 2. The land surface was in the stage of rapid movement, and the mining direction of this working face was from the southeast to the northwest. The mining velocity of this working face was about 4.5 meters per day and the mining activity was finished on 25 March 2013. 


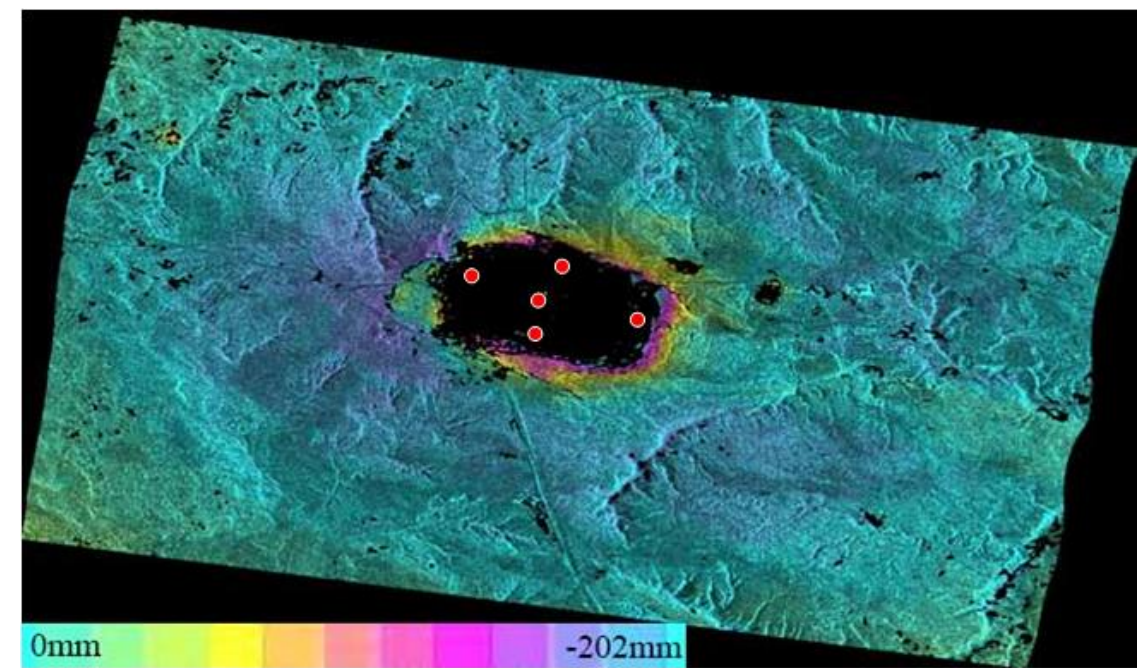

Figure 2. Subsidence generated by D-InSAR

The maximum D-InSAR monitoring of mining subsidence was about $0.202 \mathrm{~m}$, and during this period, the maximum GPS monitoring of mining subsidence was $4.365 \mathrm{~m}$, which is greater than the maximum of D-InSAR results.

In the study, to reduce the work of GPS measuring, the parameters of the probability integral method were calculated by combining the D-InSAR and the few GPS points. Firstly, D-

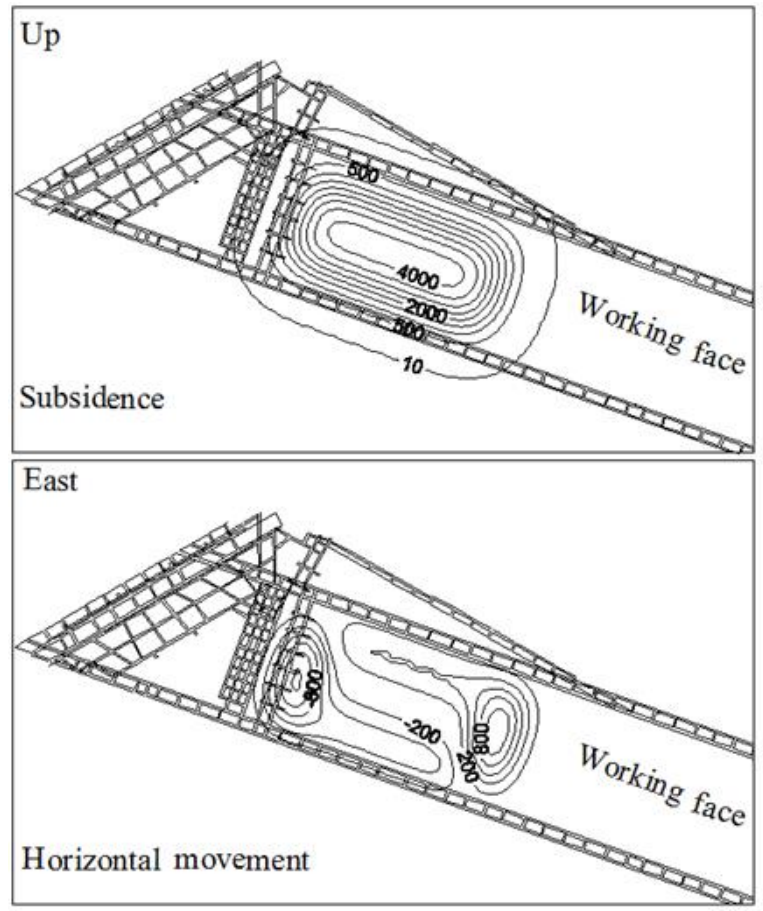

Figure 3. Three-dimensional deformation genrated by parameters
InSAR results around the subsidence edge and five observations of GPS points (the red points in figure 2) were selected, then the parameters of probability integral method are obtained by using the modulus method, the results calculated are that $\mathrm{q}=0.68$, $\tan \beta=2.22, \quad b=0.3, \quad \theta=88$. Using these parameters, threedimensional of land movement of working face can be generated, and the results were shown in Figure 3.

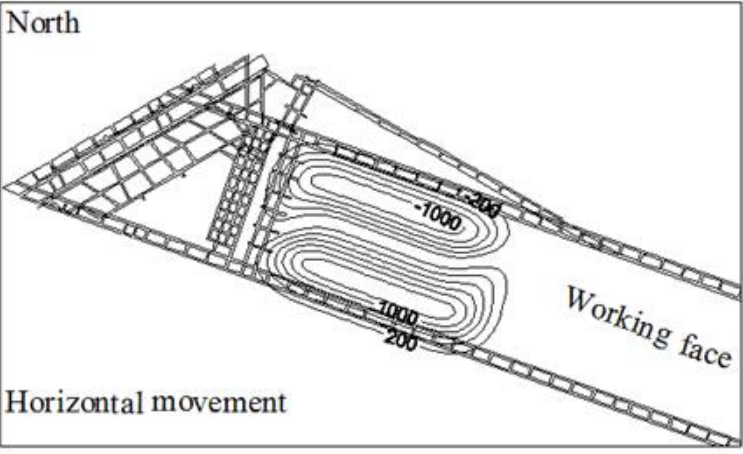

\section{西}


(2)Fusion D-InSAR techniques and probability integration method successfully extracted surface subsidence under the conditions of mining large deformation gradients. It is feasible to inverse the mining subsidence basin by using the parameters of the probability integral method, which can be obtained the combination of points in the subsidence basin edge generated by D-InSAR with a few observations.

(3)The number of surface observations can be decreased when D-InSAR technique is used. Meanwhile, the number of edge points involved in the prediction of subsidence basin is increased. On the one hand reduce the workload and cost of traditional monitoring method; On the other hand, with the increase of number of control points at basin edge, the original parameters of mining subsidence inversion exist the problem of fast convergence and others, through in-depth study, this issue is expected to be corrected in the future.

\section{ACKNOWLEDGEMENTS}

TerraSAR-X images were provided by the DLR scientific proposal LAN1173 and LAN1425. The research work has been funded by the Basic Research Project of Jiangsu Province (Natural Science Foundation) (no.BK20130174), the Special Fund for Public Projects of National Administration of Surveying, Mapping, and Geoinformation of China (no. 201412016), the Natural Science Foundation of China (no. 41272389), and the Priority Academic Program Development of Jiangsu Higher Education Institutions.

\section{REFERENCES}

Fan H D, Cheng D, Deng K Z, Chen B Q, Zhu C G, 2015. Subsidence monitoring using D-InSAR and probability integral prediction modelling in deep mining areas. Survey Review, doi: 10.1179/1752270614Y.0000000153.

Fan H D, Deng K Z, Ju C Y, 2011. Land subsidence monitoring by D-InSAR technique. Mining Science and Technology, (21), pp.869-872.

Fan H D, Deng K Z, Zhu C G, et al. Deformation monitoring and prediction methds for expressway above goaf based on time series SAR technique. Journal of China Coal Society(in Chinese), 37(11), pp.1841-1846.

Gabriel A K., Zebker H A, Goldstein R M,1989. Mapping small elevation changes over large areas: Differential radar interferometry. Journal of Geophysical Research, 94(B7), pp.9183-9191.

Zhang G H, Qu C H, Shan X J, 2011. The coseismic InSAR measurements of 2008 Yutian earthquake and its inversion for source parameters. Chinese Journal of Geophysics(in Chinese),54(11), pp.2753-2760.

Han Y F, Song X G, Shan X J, 2010. Deformation monitoring of changbaishan tianchi volcano using D-InSAR technique and error analysis. Chinese Journal of Geophysics (in Chinese) ,53(7),pp.1571-1579.

Francesca C, Batuhan O, Enrique C C, 2012. Monitoring land subsidence and its induced geological hazard with Synthetic Aperture Radar Interferometry: A case study in Morelia, Mexico. Remote Sensing of Environment, (117), pp.146-161.

$\mathrm{Ng} \mathrm{A} \mathrm{H,} \mathrm{Ge} \mathrm{L} \mathrm{L,} \mathrm{Zhang} \mathrm{K,2011.} \mathrm{Deformation} \mathrm{mapping} \mathrm{in} \mathrm{three}$ dimensions for underground mining using InSAR - Southern highland coalfield in New South Wales, Australia. International Journal of Remote Sensing,32(22), pp. 7227-7256.

Ng A H, Ge L L, Zhang K, 2012. Estimating horizontal and vertical movements due to underground mining using ALOS PALSAR. Engineering Geology, 143-144, pp.18-27.

Massonnet D, Feigl K L, 1998. Radar interferometry and its application to changes in the Earth's surface. Review of Geophysics, 36(4), pp. 441-500.

He G Q, Yang L, Ling G D, 1991. Mining subsidence (in Chinese). Xuzhou: China University of Mining and Technology Press.

Fan H D, Gu W, Qin Y, Xue J Q, Chen B Q, 2014. A model for extracting large deformation mining subsidence using D-InSAR technique and probability integral method. Transactions of Nonferrous Metals Society of China, 24(2014), pp. 1242-1247.

Revised June 2015 